\title{
Desarrollo y aplicación de una prueba de RCP para detectar la infección subclínica por Mycobacterium leprae
}

\author{
Martha Inírida Guerrero, ${ }^{1}$ María Teresa Arias, ${ }^{2}$ María Teresa Garcés ${ }^{2}$ \\ y Clara Inés León ${ }^{1}$
}

RESUMEN Objetivos. El descenso mundial de la prevalencia de la lepra no ha coincidido con un descenso de su incidencia, lo cual indica que no se ha podido prevenir la transmisión de la enfermedad. A pesar de la escasez de pacientes con lepra lepromatosa, la mayoría de los habitantes de áreas endémicas presentan signos de exposición al Mycobacterium leprae, hecho que podría explicarse por la presencia de infecciones subclínicas bacilíferas en la comunidad. El objetivo de este estudio consistió en investigar el uso de una prueba de reacción en cadena de la polimerasa (RCP) para detectar M. leprae en muestras de moco nasal de contactos intradomiciliarios, sin signos ni sintomas, de pacientes con lepra.

Métodos. Se estandarizó y optimizó una técnica de RCP para amplificar un fragmento de 321 pares de bases, utilizando un par de iniciadores complementarios a un segmento del gen LSR/A15 que codifica la proteína de $15 \mathrm{kDa}$. Se investigaron las concentraciones óptimas de todos los componentes y se utilizó dimetilsulfóxido (DMSO) para lograr una amplificación más específica. La prueba se aplicó a 70 contactos intradomiciliarios de pacientes procedentes de ocho municipios colombianos con alta prevalencia de lepra.

Resultados. El límite de detección de la prueba fue de $100 \mathrm{fg}$ de ADN. Con la técnica optimizada se detectó la presencia del bacilo en las muestras de moco nasal de 9 (12,8\%) de los 70 contactos intradomiciliarios sanos. Todos los contactos intradomiciliarios de casos paucibacilares que resultaron positivos $(n=3)$ procedían de municipios con una prevalencia muy alta. La convivencia de los contactos $\mathrm{RCP}^{+}$con los pacientes, expresada como tiempo de convivencia en relación con la edad fue significativamente menor que la de los contactos con resultados negativos en la $\operatorname{RCP}(P=0,028)$, demostrando la capacidad de detección precoz de la prueba. Conclusiones. La RCP desarrollada es útil como herramienta de detección y seguimiento precoz de posibles casos de lepra y se puede utilizar en la monitorización de poblaciones de alto riesgo y también para el mantenimiento de los logros del programa de eliminación de la lepra en países donde se ha conseguido reducir significativamente su prevalencia.

Palabras clave Lepra, $\mathrm{RCP}$, infección subclinica, vigilancia, eliminación, Colombia.

1 Laboratorio de Micobacterias. Subdirección de Investigación y Desarrollo. Instituto Nacional de Salud, Bogotá, Colombia. La correspondencia debe enviarse a Martha Inírida Guerrero, a la siguiente dirección: AA 80080 Bogotá, Colombia. Correo electrónico: mguerrerog@hemagogus.ins.gov.co

2 Departamento Administrativo de Salud del Cesar. Dasaluc, Valledupar, Colombia.
La lepra es una enfermedad infecciosa crónica que afecta a millones de personas en el mundo y presenta una prevalencia global de 1,25 casos / 10000 habitantes (1). El agente etiológico es Mycobacterium leprae, bacteria que aún no ha podido ser cultivada in vitro, por lo cual el diagnóstico de la lepra se basa en los hallazgos clínicos, junto con el examen histológico y la visualización microscópica de los bacilos ácido-alcohol resistentes en los frotis de tejidos (2). 
Desde el punto de vista epidemiológico, llama la atención que el descenso mundial de la prevalencia de la lepra no se haya acompañado de un descenso de su incidencia, es decir, que no se haya podido prevenir la transmisión, a pesar de que se haya adoptado la poliquimioterapia en programas con un seguimiento muy estricto (3). Por otro lado, a pesar de la escasez de pacientes con lepra lepromatosa, la mayoría de los habitantes de áreas endémicas presentan signos de exposición a M. leprae (3). Para esto se han buscado varias explicaciones, entre ellas que, debido al largo período de incubación de la enfermedad y a la amplia gama de presentaciones clínicas, exista una gran proporción de pacientes que se mantienen largo tiempo en la forma subclínica, en la que pueden presentar una fase bacilífera de la infección primaria, localizada en la mucosa nasal, que los convierte en un foco transitorio de diseminación de bacilos (3). Como se desconoce en gran medida la importancia de la infección subclínica y su relevancia en la transmisión de la enfermedad, la cuantificación de la proporción de casos subclínicos en una población dada podría aumentar nuestro conocimiento de la diseminación y transmisión de $M$. leprae y de los factores de riesgo. Las personas que están en contacto permanente con los enfermos son quienes tienen mayor riesgo de contraer tanto la infección como la enfermedad (1) y, por lo tanto, es importante encontrar un método rápido, sensible y específico que permita realizar un diagnóstico precoz de esta infección subclínica entre los contactos intradomiciliarios de los pacientes, con el fin de vigilar y evaluar la importancia de tales casos en la cadena de transmisión de la enfermedad (3).

La aplicación de la técnica de la reacción en cadena de la polimerasa (RCP) en la detección específica de $M$. leprae en muestras clínicas proporciona una gran sensibilidad (detección de 10 a 100 bacilos) y una especificidad del $100 \%$ (4-7). Como blancos se han utilizado diferentes secuencias, como las que codifican las proteínas antigénicas de $15 \mathrm{kDa}(8), 18 \mathrm{kDa}(9,10)$ y $36 \mathrm{kDa}$ $(11,12)$, la proteína de $65 \mathrm{kDa}(13,14)$, la secuencia repetitiva $\operatorname{RLEP}(4,15-17)$, la subunidad $16 \mathrm{~S}$ del ARNr (18) y la enzima superóxido-dismutasa (19). Entre sus aplicaciones se encuentra la detección de mutaciones específicas en genes que le puedan conferir al bacilo resistencia a la rifampicina o a las fluoroquinolonas, como las mutaciones de los genes rpob (20) y gyr $A / B$ (21), respectivamente.

En este estudio se desarrolló una RCP usando como blanco el gen $L S R / A 15$, que codifica la proteína antigénica de $15 \mathrm{kDa}$ de $M$. leprae (8), y se utilizó en muestras de moco nasal de los contactos intradomiciliarios de pacientes con lepra provenientes de municipios colombianos de alta prevalencia para detectar la presencia de infección subclínica.

\section{MATERIALES Y MÉTODOS}

Se realizó un estudio transversal en ocho municipios del departamento de Cesar, Colombia, en el que se investigaron los contactos intradomiciliarios, sin signos ni síntomas de enfermedad, de todos los casos nuevos de lepra diagnosticados durante el semestre de julio a diciembre de 1998.

En dos fichas diseñadas al efecto se registraron los datos demográficos y clínico-epidemiológicos de todos los contactos intradomiciliarios incluidos en el estudio. Posteriormente los datos se trasladaron a una base de datos Epiinfo. A partir de los datos consignados, se realizó un análisis de frecuencias de las variables de interés, asî como un análisis bivariado cuando fue posible.

Se recolectaron muestras de moco nasal de los contactos intradomiciliarios de pacientes con lepra diagnosticados histopatológica y clínicamente entre julio y diciembre de 1998 por el programa local de control de lepra del departamento de Cesar, Colombia. Las muestras fueron tomadas en el centro de salud de cada municipio, utilizando hisopos de algodón y realizando movimientos rotatorios sobre el tabique nasal. Los hisopos fueron colocados en tubos de ensayo nuevos, estériles, de cierre hermético, y en 24 horas fueron enviados, refrigerados, al Instituto Nacional de Salud (INS) en Bogotá. A cada tubo de ensayo con el hisopo se le añadieron $1500 \mathrm{~mL}$ de tampón Tris$\mathrm{HCl} 1 \mathrm{mM}$, se agitó fuertemente el hisopo dentro del tampón y la suspensión obtenida se dividió en tres alícuotas de $500 \mathrm{~mL}$ que fueron congeladas a $-70^{\circ} \mathrm{C}$ hasta su utilización.

Como controles positivos se utilizaron bacilos aislados a partir de tejido del cojinete plantar de ratones BALB/c inoculados 12 meses antes, según el protocolo recomendado por la OMS (22). La cuantificación de los bacilos ácido-alcohol resistentes se realizó en frotis teñidos con la coloración de Ziehl-Neelsen (2). Además, también se utilizaron bacilos obtenidos a partir de muestras de lepromas de un paciente con lepra lepromatosa diagnosticado recientemente, usando el protocolo recomendado por la OMS para el procesamiento de las biopsias (22). Como controles negativos se utilizaron muestras de agua ultrapura y cultivos de otras micobacterias: $M$. chelonae, $M$. fortuitum, M. avium-intracellulare, $M$. bovis, $M$. bovis var $B C G, M$. tuberculosis $H_{37} R v$, M. vacae y $M$. kansasii, obtenidas de la micobacterioteca del Laboratorio de Micobacterias del INS, las cuales se resuspendieron en el mismo tampón Tris- $\mathrm{HCl} 1 \mathrm{mM}$.

El proceso de extracción del ADN cromosómico de los controles se realizó utilizando dos métodos: el enzimático y el de choque térmico. El método de choque térmico consistió en someter la suspensión a ebullición durante 5 minutos, y luego a 6 ciclos de ebullición y congelación en nitrógeno líquido (23). En el método enzimático se añadió lisozima $(2 \mathrm{mg} / \mathrm{mL})$, se incubó a $37^{\circ} \mathrm{C}$ durante una hora y posteriormente se añadió proteinasa K (100 $\mathrm{mg} / \mathrm{mL}$ ) y dodecilsulfato sódico (SDS) al $10 \%$. El ADN extraído se purificó utilizando igual volumen de fenol:cloroformo (24:1) seguido de dos lavados por centrifugación, primero con etanol absoluto y después con etanol al 70\% (23). El ADN purificado fue reconsti- 
tuido con $25 \mathrm{~mL}$ de agua ultrapura, se cuantificó por visualización en gel de agarosa al $0,8 \%$ y se guardó a $-70{ }^{\circ} \mathrm{C}$ hasta su utilización. La extracción del ADN de los cultivos de las otras micobacterias se realizó según la metodología estándar (24).

En la RCP se amplificó un fragmento de 321 pares de bases, usando los oligonucleótidos MIG1, entre los nucleótidos 290 y 309 (5'-CGAAGAAGTGACCGTCAACC-3'), y MIG2, entre los nucleótidos 609 y 628 (5'AATGCGTCAATGACGTCGGC-3') (Gibco Life Technologies, Carlsbad, CA, EE.UU.), en un termociclador Amplitron I ${ }^{\circledR}$ (Barnstead/Thermolyne, Dubuque, IA, EE.UU.). Se obtuvo una buena amplificación usando las concentraciones estándar recomendadas habitualmente por el proveedor de la polimerasa Taq (Amersham Life Science, Piscataway, NJ, EE.UU.). Para visualizar el producto de la RCP se realizó una electroforesis sembrando 15 $\mathrm{mL}$ de la muestra en el tampón de migración, constituido por azul de bromofenol al 0,05\%, sacarosa al $40 \%$, EDTA 0,1 M (pH 8,0) y SDS al 0,5\%, utilizando como marcador de peso molecular el fX174/Hae III Digest (Sigma Chemical, St. Louis, MO, EE.UU.).

Los componentes y condiciones de la prueba estándar fueron optimizados empleando diferentes concentraciones de trifosfatos de desoxirribonucleósidos (dNTP; 1, 2, 3 y 4 mM; Sigma Chemical), de $\mathrm{MgCl}_{2}(0,0,5,1,1,5$ y 2 mM; Amersham Life Science), de cada uno de los iniciadores $(0,25,0,5,0,75,1$ y 1,25 mM; Gibco Life Technologies), de polimerasa Taq $(0,5,1,1,25$ y 1,5 unidades; Amersham Life Science) y de dimetilsulfóxido (DMSO) al 10\% (0, 2,5, 3,5, 4,5 y 5,5 ml; Sigma Chemical) $(25,26)$. Las temperaturas de hibridación probadas fueron de 45, 48, 50, 52 y $55^{\circ} \mathrm{C}$, y el número de ciclos de amplificación de 30, 35, 40 y 45. Para visualizar los productos de la RCP se emplearon geles de agarosa al 2 a $4 \%$, coloreados con bromuro de etidio tras la polimerización de la agarosa.

Para determinar el límite de detección de la RCP optimizada se utilizaron cantidades decrecientes de $1 \mathrm{mg}$ a $1 \mathrm{fg}$ de ADN de M. leprae extraído y purificado a partir del cojinete plantar del ratón $\mathrm{BALB} / \mathrm{c}$.

El control de calidad se realizó con la metodología descrita por Santos et al. (4), quienes nos suministraron sus iniciadores.

A todas las muestras negativas se les añadieron $100 \mathrm{fg}$ de ADN de M. leprae, y se repitió la prueba con el fin de evidenciar la presencia de inhibidores de la polimerasa Taq.

\section{RESULTADOS}

Se obtuvieron muestras de moco nasal de 70 contactos intradomiciliarios de 22 pacientes con lepra diagnosticados clínica e histopatológicamente entre julio y diciembre de 1998 por el programa local de control de lepra del departamento de Cesar, Colombia; 14 pacientes fueron clasificados como multibacilares (MB) y 8 como paucibacilares (PB), según la clasificación de la OMS (2).

De los dos métodos de extracción del ADN de los controles positivos, con el de digestión enzimática se obtuvo mayor cantidad que con el de choque térmico; la diferencia fue de 1 a $10 \mathrm{ng} / \mathrm{mL}$.

Después de probar las diferentes concentraciones y condiciones de realización de la prueba, se verificó que la concentración óptima de $\mathrm{MgCl}_{2}$ era de $1 \mathrm{mM}$; la de dNTP, de $2 \mathrm{mM}$; la de iniciadores, de 0,75 mM; la de la enzima, de 1,25 unidades/prueba, y la de DMSO, de 0,9\%. Se comprobó que la temperatura óptima en la fase de unión de los iniciadores a la cadena de ADN blanco fue de $48{ }^{\circ} \mathrm{C}$ y que se obtuvo una banda específica con 35 ciclos de amplificación. Para la visualización óptima de los productos de amplificación se escogió la agarosa al 3\%.

Por lo tanto, finalmente la amplificación se realizó satisfactoriamente usando $50 \mathrm{~mL}$ de una mezcla de reacción que tenía las condiciones óptimas, de la siguiente forma: $5 \mathrm{~mL}$ de tampón RCP10X; $2 \mathrm{~mL}$ de $\mathrm{MgCl}_{2}$ (25 mM); $4 \mathrm{~mL}$ de mezcla de dNTP ( $25 \mathrm{mM}$ cada uno); 0,25 $\mathrm{mL}(5,0 \mathrm{U} / \mathrm{ml})$ de polimerasa Taq; $1,5 \mathrm{~mL}(25 \mathrm{mM})$ de cada iniciador; 4,5 $\mathrm{mL}$ de DMSO $(10 \%)(25,26)$, y $25,75 \mathrm{~mL}$ de agua ultrapura; cada mezcla de reacción fue cubierta con aceite mineral (Sigma Chemical) y, por último, se colocaron $10 \mathrm{~mL}$ del ADN extraído. La mezcla de reacción se sometió a un ciclo de desnaturalización de 3 minutos a $96{ }^{\circ} \mathrm{C}$, seguido por 35 ciclos de 1 minuto a $96^{\circ} \mathrm{C}, 1$ minuto a $48^{\circ} \mathrm{C}$ y $1 \mathrm{mi}$ nuto a $72{ }^{\circ} \mathrm{C}$. Finalmente, se sometieron a un ciclo de 5 minutos a $72{ }^{\circ} \mathrm{C}$. Los productos de la RCP se visualizaron mediante electroforesis en gel de agarosa al 3\%. La técnica optimizada detectó hasta $100 \mathrm{fg}$ de ADN (figura 1).

Se procesaron 70 muestras de moco nasal de los contactos intradomiciliarios de los pacientes y se detectó ADN de $M$. leprae en 9 de ellas $(12,8 \%$ ) (figura 2). El ADN de los dos controles positivos incluidos se amplificó en todos los casos (figura 2). El agua ultrapura y las otras micobacterias utilizadas como controles negativos no se amplificaron en ningún caso. Las 61 muestras inicialmente negativas fueron positivas después de añadir ADN de M. leprae, descartando así la presencia de inhibidores. En el control de calidad, al probar las 70 muestras de moco nasal con la técnica de Santos et al. (4) se obtuvieron resultados iguales en cuanto a la positividad de las muestras y a la ausencia de inhibidores de la reacción.

Los contactos estudiados, sin signos ni síntomas de enfermedad, provenían de ocho municipios colombianos con alta prevalencia de lepra (cuadro 1); 44

\section{FIGURA 1. Límite de detección de la RCP: banda amplificada de 321 pares de bases del gen LSR/A15 de M. leprae. Carril 1: ADN de $M$. leprae de leproma; carril 2: control negativo, y carriles 3 a 8: ADN de $M$. leprae del cojinete plantar: $1 \mu \mathrm{g}, 100 \mathrm{pg}, 1 \mathrm{pg}, 100$ $\mathrm{fg}, 10 \mathrm{fg}$ y $1 \mathrm{fg}$, respectivamente}

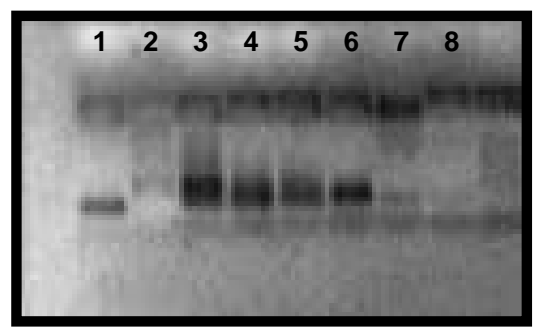


FIGURA 2. Fragmentos de amplificación de 321 pares de bases del gen LSR/A15 de M. leprae. Carril 1: ADN de M. leprae de cojinete plantar; carril 2: ADN de M. leprae de leproma; carril 3: control negativo, y carriles 4 a 20: muestras del 1 al 16

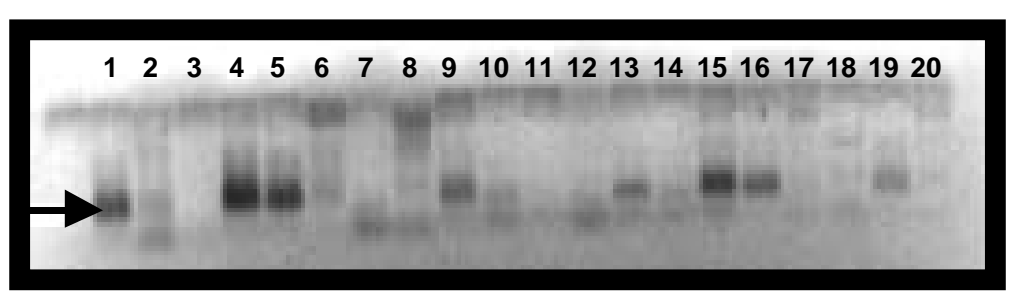

de ellos $(62,8 \%)$ eran contactos intradomiciliarios de casos MB, y 26 (37,2\%) de casos PB; el $42 \%$ eran hombres y el $58 \%$, mujeres, y los antecedentes de vacunación con BCG fueron positivos en el $56 \%$, negativos en el $37 \%$ y desconocidos en el $7 \%$. El 67\% de los contactos tenían un parentesco en primer grado con el caso índice, el 9\% en segundo grado, el 17\% eran sus cónyuges y el $7 \%$ no tenían relación de parentesco. El $67 \%$ de los contactos eran de procedencia urbana y el 33\% de procedencia rural. El promedio de convivientes por caso índice fue de 3,18 personas (1 a 8). El 77\% eran contactos de casos índice del sexo masculino, y el $23 \%$ de casos índice del sexo femenino.

El 50\% de los convivientes tenían 21 años o más, con un promedio de 23,9 años, mientras que el $50 \%$ de los casos índice tenían 32 años o más, con una media de 34,5 años. El 50\% de los convivientes habían vivido con el caso ín- dice 9 años o más (media de 11,2 años). Relacionando el tiempo de convivencia con la edad del conviviente, se verificó que el 50\% de los convivientes habían convivido el $58 \%$ de su vida con el caso índice $\mathrm{y}$, en promedio, el $62 \%$ de su vida. El $50 \%$ de los convivientes procedían de municipios con una prevalencia $\geq 2,5 / 10000$ habitantes y el $61 \%$ eran convivientes de un caso índice sin discapacidades.

El análisis de frecuencias de las variables discriminadas entre convivientes $\mathrm{RCP}^{+}$y $\mathrm{RCP}^{-}$y los resultados de los análisis bivariados realizados se muestran en los cuadros 2 y 3. Se encontró una mayor probabilidad de infección entre los cónyuges que entre el resto de los convivientes con parentesco o sin él [razón de posibilidades $(\mathrm{OR})=3,87$; intervalo de confianza del 95\% (IC95\%): 1,21 a 12,3]. Los convivientes con infección subclínica presentaron una convivencia significativamente menor $(P=$

CUADRO 1. Distribución de los contactos intradomiciliarios con RCP positiva para $M$. leprae según la prevalencia de lepra en el municipio y el tipo de caso índice. Cesar, Colombia, 1998

\begin{tabular}{ccccc}
\hline Municipio & Prevalencia $^{\mathrm{a}}$ & $\begin{array}{c}\text { Casos } \\
\text { nuevos }\end{array}$ & $\begin{array}{c}\text { Contactos } \\
\text { investigados }\end{array}$ & $\begin{array}{c}\text { Contactos } \\
\text { RCP+/caso }\end{array}$ \\
\hline 1 & 8,5 & 3 & 12 & $1 / 1(\mathrm{~PB})^{\mathrm{b}}$ \\
2 & 5,7 & 2 & 7 & $1 / 1(\mathrm{MB})$ \\
3 & 5,0 & 1 & 5 & 0 \\
4 & 3,6 & 2 & 5 & $2 / 2(\mathrm{~PB})$ \\
5 & 2,5 & 4 & 14 & 0 \\
6 & 2,4 & 5 & 18 & $2 / 1(\mathrm{MB})$ \\
7 & 2,4 & 2 & 5 & $2 / 1(\mathrm{MB})$ \\
8 & 1,2 & 3 & 4 & $1 / 1(\mathrm{MB})$ \\
\hline
\end{tabular}

Fuente: Departamento Administrativo de Salud del Cesar. Dasaluc.

a Por 10000 habitantes.

${ }^{b} \mathrm{~PB}=$ paucibacilares. $\mathrm{MB}=$ multibacilares

$0,028)$ que los convivientes sin infección subclínica; al discriminar entre los convivientes de casos índice MB, la diferencia siguió siendo significativa $(P=0,045)$.

\section{DISCUSIÓN}

En el presente estudio se estandarizó la técnica de la RCP para detectar $M$. leprae en el moco nasal, utilizando el gen LSR/A15 como secuencia blanco. El bacilo posee una única copia de este gen en su genoma, lo que incrementa enormemente la especificidad de la prueba. Comparativamente, cuando se usa como blanco una secuencia repetitiva, la sensibilidad aumenta mucho, como en el caso de la prueba desarrollada por Santos et al. (4), pero generalmente a expensas de la especificidad.

Nuestra prueba alcanzó un límite de detección de 100 fg de ADN (correspondiente a unos 10 a 100 bacilos), similar al que obtuvieron Misra et al. (8), y no hubo reacción cruzada con ninguna de las otras ocho especies micobacterianas analizadas, lo cual indica que estamos frente a una valiosa herramienta utilizable en el diagnóstico precoz de la infección. Es importante destacar que con la prueba desarrollada por Santos et al. (4), que posee un límite de detección 100 veces mayor que nuestra prueba, la reactividad de las muestras de moco nasal fue igual, lo cual demuestra una buena sensibilidad de la técnica estandarizada. La aplicación de esta prueba a los contactos intradomiciliarios permitirá detectar nuevos casos antes que la baciloscopia, cuya sensibilidad es 500 veces menor (27).

En el presente estudio utilizamos muestras de moco nasal teniendo en cuenta que las vías respiratorias altas, y especialmente la mucosa de las fosas nasales, son una de las principales vías de transmisión $(3,27)$. Como han sugerido previamente varios investigadores $(12,13,17)$, no se puede descartar la posibilidad de encontrar "portadores pasivos" que, sin tener infección subclínica, tengan bacilos en sus fosas nasales; sin embargo, esto no invalida la utilidad de la prueba para la monitori- 
CUADRO 2. Distribución de variables categóricas entre los contactos intradomiciliarios de nuevos casos de lepra, según el resultado de la RCP en el moco nasal. Cesar, Colombia, 1998

\begin{tabular}{|c|c|c|c|}
\hline Variable & $\begin{array}{l}\mathrm{RCP}^{+} \\
n(\%)\end{array}$ & $\begin{array}{l}\mathrm{RCP}^{-} \\
n(\%)\end{array}$ & Valor $P^{a}$ \\
\hline \multicolumn{4}{|l|}{ Sexo } \\
\hline Masculino & $3(10,3)$ & $26(89,7)$ & \multirow[t]{2}{*}{0,597} \\
\hline Femenino & $6(14,6)$ & $35(85,4)$ & \\
\hline \multicolumn{4}{|c|}{ Antecedentes de BCG } \\
\hline Sí & $6(15,4)$ & $33(84,6)$ & \multirow[t]{2}{*}{0,660} \\
\hline No & $3(11,5)$ & $23(88,5)$ & \\
\hline \multicolumn{4}{|l|}{ Procedencia } \\
\hline Rural & $5(21,7)$ & $18(78,3)$ & \multirow[t]{2}{*}{0,120} \\
\hline Urbana & $4(8,5)$ & $43(91,5)$ & \\
\hline \multicolumn{4}{|l|}{ Prevalencia municipio } \\
\hline$\leq 2,5 / 10000 \mathrm{hab}$ & $5(12,2)$ & $36(87,8)$ & \multirow[t]{2}{*}{0,840} \\
\hline$>2,5 / 10000 \mathrm{hab}$ & $4(13,8)$ & $25(86,2)$ & \\
\hline \multicolumn{4}{|l|}{ Caso índice } \\
\hline MB & $6(13,6)$ & $38(86,4)$ & \multirow[t]{3}{*}{0,800} \\
\hline PB & $3(11,5)$ & $23(88,5)$ & \\
\hline Total & $9(12,8)$ & $61(87,2)$ & \\
\hline
\end{tabular}

a Prueba de la $x^{2}$

b Desconocidos en 5 contactos.

CUADRO 3. Distribución de variables continuas entre los contactos intradomiciliarios de nuevos casos de lepra, según el resultado de la RCP en el moco nasal. Cesar, Colombia, 1998

\begin{tabular}{lccc}
\hline \multicolumn{1}{c}{ Variable } & $\begin{array}{c}\mathrm{RCP}^{+} \\
\text {media (intervalo) }\end{array}$ & $\begin{array}{c}\mathrm{RCP}^{-} \\
\text {media (intervalo) }\end{array}$ & Valor $P^{\mathrm{a}}$ \\
\hline Edad (años) & $29,66(2-62)$ & $22,97(1-76)$ & 0,2732 \\
Tiempo de convivencia (años) & $7(2-18)$ & $11,9(1-44)$ & 0,1953 \\
Tiempo de convivencia/edad (años) & $0,382(0,0577-1)$ & $0,667(0,698-1)$ & $0,0288^{\mathrm{b}}$ \\
\hline
\end{tabular}

a Prueba de Wilcoxon.

b Valor estadísticamente significativo.

zación poblacional de comunidades de alto riesgo. En este estudio se comprobó que las personas examinadas no rechazan la toma de muestras, debido a la facilidad para obtenerlas y a su carácter incruento.

Controlando todos los factores inhibidores presentes en la muestra y optimizando todas las condiciones necesarias ya descritas, se obtiene una buena amplificación que proporciona una nueva herramienta para el manejo del programa de control de la lepra en el ámbito local tanto como en el nacional.

El porcentaje de casos positivos detectados en este estudio (12,8\%; IC95\%: 6,3 a 23) es similar al registrado en estudios anteriores $(3,27,28)$ que también utilizaron la RCP en el moco nasal (del 3 al 9\%), lo cual confirma la utilidad de esta prueba en la detección de la infección subclínica.

Los cónyuges de los casos índice presentaron una probabilidad de infección tres veces mayor que el resto de los convivientes, con o sin relaciones de parentesco, debido a que se requiere un contacto cercano y prolongado para una transmisión óptima $(3,27)$, la cual, al parecer, se presenta en grupos. En este sentido, tanto el tiempo de convivencia como la fracción de la vida pasada en convivencia (cuadro 3) revelaron que los convivientes con infección subclínica requirieron una convivencia significativa- mente menor $(P=0,028)$ para infectarse, diferencia que siguió siendo significativa $(P=0,045)$ al discriminar entre los convivientes de casos índice $\mathrm{MB}$; esto muestra la especificidad y capacidad de detección precoz de la infección subclínica y, por ende, la utilidad de la prueba. Aunque se verificó que el $61 \%$ de los convivientes lo eran de casos índice sin discapacidad, queda el interrogante de si existe alguna relación entre la positividad de la RCP de los convivientes y el tiempo de evolución de los síntomas antes del diagnóstico del caso índice, es decir del período de infecciosidad.

Con relación a la transmisión, otra observación llamativa pero que no llegó a ser significativa, posiblemente por el pequeño tamaño de la muestra, fue la mayor procedencia rural $(P=$ $0,161)$ de los convivientes infectados con $\mathrm{RCP}^{+}$(cuadro 2), que se explicaría por la mayor posibilidad de supervivencia del bacilo en condiciones de vivienda subóptimas (3). No obstante, al revisar las estadísticas colombianas de los nuevos casos de lepra (29) se observa que son principalmente urbanos, discrepancia que seguramente puede explicarse por la centralización de la atención (30).

Creemos que la principal utilidad de esta técnica de RCP será la posibilidad de poner en práctica un sistema de vigilancia que permita realizar una monitorización de las poblaciones de alto riesgo para detectar precozmente la enfermedad, mejorar la búsqueda activa de los casos y mantener los logros alcanzados por los programas locales de control de la lepra, que en condiciones de baja prevalencia o posteliminación deben mostrar indicadores tales como: prevalencia $<1,0310^{-4}$; tasa nula de nuevos casos detectados en menores de 15 años; tasa de nuevos casos detectados en mayores de 15 años $\leq 2,0$ $310^{-5}$; tasa de nuevos casos detectados tardíamente $\leq 1310^{-5}$; proporción de casos con poliquimioterapia regular $>80 \%$; proporción de casos curados $>90 \%$, y proporción de abandono de la poliquimioterapia $<5 \%$ (31).

Asimismo, esta técnica de RCP permitirá realizar estudios de seguimiento individuales y estudios epidemiológi- 
cos de la distribución y comportamiento de la lepra en un país o área determinada. Como sugiere la Organización Panamericana de la Salud (29), lo que proponemos aquí es hacer uso de las nuevas tecnologías que permitan interrumpir la cadena de transmisión de esta enfermedad, puesto que cuando analizamos los indicadores de incidencia y prevalencia de Colombia (30) se observa lo que se ha visto también en otros países, es decir, un estancamiento de la disminución de la incidencia en los últimos años, a pesar de que la prevalencia muestra un descenso, que también parece haberse estancado, y de que se tiene una cobertura casi total de la poliquimioterapia (30).
Si consideramos a Colombia como un país en período de posteliminación de la lepra como problema de salud pública, debido a su tasa de prevalencia inferior a 1/10 000 habitantes, estaríamos en la necesidad de mantener estos logros, lo cual solamente se puede conseguir con estrategias de vigilancia adecuadas. Por eso es importante conocer la forma como se está moviendo la carga bacilar en la comunidad, preferiblemente discriminando el comportamiento por municipio o localidad.

En resumen, la detección mediante RCP del M. leprae en muestras de moco nasal de contactos intradomiciliarios sanos de los pacientes constituye un valioso método para detectar la pre- sencia de infección subclínica que en el futuro podría ayudar a mejorar el funcionamiento del Programa de Control de la Lepra.

Agradecimientos. A los investigadores Adalberto Santos, Ph.D., y Philip Suffys, Ph.D, del Instituto FioCruz por la donación de sus iniciadores; a E. Castañeda, Ph.D., y J. Cuervo, MD, MSc, por sus sugerencias y discusión de nuestros resultados; a Ernesto Prats León, MD, por su aporte práctico, y al Hospital Simón Bolívar por la colaboración para el desarrollo de este trabajo. Este estudio se desarrolló gracias a la financiación del Instituto Nacional de Salud de Colombia y de la Fundación FioCruz de Brasil.

\section{REFERENCIAS}

1. World Health Organization. Fact Sheets. Leprosy; 2001. [Sitio en Internet] WHO. Disponible en: http://www.who.int/inf-fs/en/fact101. $\mathrm{html}$. Acceso el 4 de marzo de 2002.

2. Guerrero MI, León CI, Naranjo N, Orozco LC, de Blanco E, Camargo D, et al. El laboratorio en lepra: bacteriología y patología. Manual de procedimientos básicos. Santa Fe de Bogotá DC: Instituto Nacional de Salud; 1992.

3. Cree IA, Smith WC. Leprosy transmission and mucosal immunity: towards eradication? Lepr Rev 1998;69:112-121.

4. Santos AR, De Miranda AB, Sarno EN, Suffys PN, Degrave WM. Use of RCP-mediated amplification of Mycobacterium leprae DNA in different types of clinical samples for the diagnosis of leprosy. J Med Microbiol 1993;39: 298-304.

5. Wolcott MJ. Advances in nucleic acid-based detection methods. Clin Microbiol Rev 1992;5: 370-386.

6. Job CK, Jayakumar J, Williams DL, Gillis TP. Role of polymerase chain reaction in the diagnosis of early leprosy. Int J Lepr Other Mycobact Dis 1997;65:461-464.

7. Erlich HA, Gelfand DH, Saiki RK. Specific DNA amplification. Nature 1988;331:461-462.

8. Misra N, Ramesh V, Misra RS, Narayan NPS, Colston MJ, Nath I. Clinical utility of LSR/ A15 gene for Mycobacterium leprae detection in leprosy tissues using the polymerase chain reaction. Int J Lepr Other Mycobact Dis 1995;63: 35-41.

9. Williams DL, Gillis TP, Booth RJ, Looker D, Watson JD. The use of a specific DNA probe and polymerase chain reaction for the detec- tion of Mycobacterium leprae. J Infect Dis 1990; 162:193-200.

10. Sharma RK, Katoch $K$, Shivannavar CT, Sharma VD, Natrajan M, Bhatia AS, et al. Detection of Mycobacterium leprae by gene amplification, combined ethidium-bromide staining and probe hybridization. Int J Lepr Other Mycobact Dis 1996;64:409-416.

11. Rafi A, Donoghue HD, Stanford JL. Application of polymerase chain reaction for the detection of Mycobacterium leprae DNA in specimens from treated leprosy patients. Int J Lepr Other Mycobact Dis 1995;63:42-47.

12. De Wit MY, Douglas JT, McFadden J, Klatser PR. Polymerase chain reaction for detection of Mycobacterium leprae in nasal swab specimens. J Clin Microbiol 1993;31:502-506.

13. De Wit MY, Faber WR, Krieg SR, Douglas JT, Lucas SB, Montreewasuwat N, et al. Application of a polymerase chain reaction for the detection of Mycobacterium leprae in skin tissues. J Clin Microbiol 1991;29:906-910.

14. Hartskeerl RA, De Wit MY, Klatser PR. Polymerase chain reaction for the detection of $M y$ cobacterium leprae. J Gen Microbiol 1989;135: 2357-2364.

15. Yoon KH, Cho SN, Lee MK, Abalos RM, Cellona RV, Fajardo TT Jr., et al. Evaluation of polymerase chain reaction amplification of Mycobacterium leprae-specific repetitive sequence in biopsy specimens from leprosy patients. J Clin Microbiol 1993;31:895-899.

16. Chemouilli P, Woods S, Said G, Cole ST. Detection of Mycobacterium leprae in nerve lesions by the polymerase chain reaction. Int J Lepr Other Mycobact Dis 1996;64:1-5.
17. Santos AR, Goes Filho JT, Nery JA, Duppre NC, Gallo ME, Suffys PN, et al. Evaluation of RCP mediated DNA amplification in noninvasive biological specimens for subclinical detection of Mycobacterium leprae. FEMS Immunol Med Microbiol 1995;11:113-120.

18. Pattyn SR, Ursi D, Ieven M, Raes V, Jamet P. Polymerase chain reaction amplifying DNA coding for species-specific rRNA of Mycobacterium leprae. Int J Lepr Other Mycobact Dis 1992;60:234-243.

19. Mostafa HM, Kazda J, Irgens LM, Luesse HG. Acid-fast bacilli from former leprosy regions in coastal Norway showing RCP positivity for Mycobacterium leprae. Int J Lepr Other Mycobact Dis 1995;63:97-99.

20. Honore N, Perrani E, Telenti A, Grosset J, Cole ST. A simple and rapid technique for the detection of rifampin resistance in Mycobacterium leprae. Int J Lepr Other Mycobact Dis 1993;61:600-604.

21. Cambau E, Perani E, Guillemin I, Jamet P, Ji B. Multidrug-resistance to dapsone, rifampicin and ofloxacin in Mycobacterium leprae. Lancet 1997;349:103-104.

22. World Health Organization. Laboratory techniques for leprosy. Geneva: WHO; 1982. pp. 134-136. (WHO/CDS/LEP/86.4).

23. Zhang ZQ, Ishaque $M$. Evaluation of methods for isolation of DNA from slowly and rapidly growing mycobacteria. Int J Lepr Other Mycobact Dis 1997;65:469-476.

24. Groenen PM, Bunschoten AE, van Soolingen D, van Embden JD. Nature of DNA polymorphism in the direct repeat cluster of $M y \mathrm{co}^{-}$ bacterium tuberculosis; application for strain 
differentiation by a novel typing method. Mol Microbiol 1993;10:1057-1065.

25. Bookstein R, Lai CC, To H, Lee H, Lee WH. RCP-based detection of a polymorphic Bam $\mathrm{HI}$ site in intron 1 of the human retinoblastoma (RB) gene. Nucleic Acids Res 1990;18:1666.

26. Winship PR. An improved method for directly sequencing RCP amplified material using dimethyl sulphoxide. Nucleic Acids Res 1989;17:1266.

27. Ramaprasad P, Fernando A, Madhale S, Rao JR, Edward VK, Samson PD, et al. Transmission and protection in leprosy: indications of the role of mucosal immunity. Lepr Rev 1997; 68:301-315.

28. Gillis TP, Cho SN. Report of workshop on new tools for diagnosis and epidemiology. Int J Lepr Other Mycobact Dis 1998;66: 594-595.

29. Guerrero MI, Plazas N, León CI. Situación de la lepra en Colombia: un análisis crítico. Informe Quincenal Epidemiológico Nacional 2000;5:12-22.

30. Organización Panamericana de la Salud. Eliminación de la lepra en las Américas. Bol Epidemiol OPS 2000;21:5-6.
31. González-Ochoa CE, Abreu A. Vigilancia de la lepra en situaciones de baja prevalencia. Rev Panam Salud Publica 2001;9:94-101.

Manuscrito recibido el 11 de febrero de 2002. Aceptado para publicación el 22 de febrero de 2002.

ABSTRACT Objective. While the prevalence of leprosy has declined around the world, there has not been a corresponding decrease in its incidence, thus indicating that it has not been possible to prevent transmission of the disease. Despite the small number of patients

Developing and using a PCR test to detect subclinical Mycobacterium leprae infection with lepromatous leprosy, the majority of the inhabitants of endemic areas show signs of exposure to Mycobacterium leprae, which could be explained by the presence of subclinical bacilliferous infections in the community. The objective of this study was to investigate the use of a polymerase chain reaction (PCR) test to detect $M$. leprae in samples of nasal mucus from asymptomatic household contacts of patients with leprosy. Methods. We standardized and optimized a PCR technique to amplify a 321 base pair DNA fragment, using a pair of primers complementary to a segment of an LSR/ A15 gene that codes for the $15 \mathrm{kDa}$ M. leprae antigen. We investigated the optimal concentrations of all the test components. We used dimethyl sulfoxide (DMSO) to achieve a more specific amplification. We applied the PCR test to 70 healthy household contacts of leprosy patients from eight municipalities in Colombia where there was a high prevalence of the disease.

Results. The test's detection limit was $100 \mathrm{fg}$ of DNA. With the optimized technique, bacillus was detected in the nasal mucus samples of $9(12.8 \%)$ of the 70 household contacts. The 3 PCR-positive household contacts of paucibacillary cases were from municipalities with very high prevalence levels. In comparison to contacts who were PCR-negative, the contacts who were PCR-positive had spent significantly less time, as a proportion of their age, living with a patient $(P=0.028)$. This finding demonstrates the test's capacity for early detection.

Conclusions. The PCR test that we developed is useful as a tool for detection and early follow-up of possible leprosy cases. It can be used to monitor high-risk populations and also to maintain the achievements of leprosy elimination programs in countries where the disease's prevalence has been significantly reduced. 